\title{
COMBINING GIS AND FOREST FIRE SIMULATION IN A VIRTUAL REALITY ENVIRONMENT FOR ENVIRONMENTAL MANAGEMENT
}

\author{
Sébastien Thon, Eric Remy, Romain Raffin, Gilles Gesquière \\ Laboratory LSIS (UMR CNRS 6168), LXAO team - http://www.Isis.org \\ Tel:+33 490522410 - Fax:+3349052 2415 \\ University of Aix-Marseille, IUT de Provence, rue Raoul Follereau, 13200 Arles, France \\ \{sebastien.thon, eric.remy, romain.raffin, gilles.gesquiere\}@up.univ-mrs.fr
}

Remisión Artículo: 15-5-2007

Palabras Clave: Virtual reality, urban areas, brush-clearing

Resumen. Millions of hectares of forest are destroyed by fire worldwide each year. In order to prevent this ecological and economic disaster, the efficiency of brushwood clearing operations has been proven. It is especially important around urban areas where human lives and properties are at risk. However in France, even if such operations are imposed by the law, it is not always followed in practice especially due to a lack of information. In this paper, we propose a tool designed for pedagogical and decision making purposes to demonstrate the benefits of brushwood clearing operations. Our application allows to simulate and to visualize a fire spread on real areas under different brush-clearing conditions graphically defined by the user. The core of our application is a 3D visualization of a fire spread model combined with a Geographic Information System (GIS).

\section{Introduction}

Each year, particularly during summer, several million hectares of forests are destroyed worldwide by fire. These fires can sometimes reach catastrophic proportions. For example, Portugal lost $25 \%$ of its forests in the last five years (including 424,000 hectares in 2003). In France, the area endangered by forest fires covers approximately 5 million hectares. In 2003, for the 15 departments of south-east of France, 61,507 hectares of forests were destroyed (Promethée, 2006). In order to prevent these ecological, human and financial disasters, it is important to take preventive actions. By ensuring that clearing is efficiently done on an important surface of forest, the firemen take an active part in reducing the number of fire breakouts and in reducing the fire propagation speed. These important actions contribute to the preservation of natural spaces and to the safety of fire fighters. By their continuous presence all along the year in the natural sites of France, firemen have gained a perfect knowledge of the terrain and of its topography. They can thus bring invaluable information to the populations about the risks and what kinds of actions should be avoided. They can also recall that terrain clearance is governed by the French law (32nd article of the loi d'orientation sur la forêt of 2001). Unfortunately, these awareness campaigns do not always convince people.

It would be interesting to use Information and Communication Technologies (ICT) as teaching tools to help in such awareness campaigns. The goal would be to show the interest of brushclearing to elected persons, decisions makers and land owners with the help of a computer simulation. Such simulation should use 3D computer imaging to show the propagation of forest fire on a 3D representation of a real landscape. However, such pedagogical tool does not exist. 
Fire professionals own dedicated software, but these are too specific and too complex to be used by a non-specialist or even to be shown to a non-specialist. For example, French firemen own tactical management products. "Firetactic" allows to track the location of units on two dimensional maps and to simulate the fire spread (Picard, 2004). A simplified three dimensional view can be obtained with "CartoHub" (CartoHub, 2006). A similar application named "EVE" is used during firemen training, with a fire spread manually managed by the teacher. Scientific simulations of forest fire spread have also been developed, but they are usually rather complex to use because many specific parameters must be provided..

In this article, we present a software that we developed in collaboration with the French firemen to help them in their awareness campaigns. This application combines a simulation of fire propagation with a Geographic Information System (GIS) and a real-time three dimensional visualization. This application has been designed to be used by even non specialists of fires or simulation software. Thanks to very intuitive tools, the user has the possibility to simulate brush clearing or the planting of new tree species on 3D representation of real landscapes. A forest fire can then be simulated anywhere on this landscape and visualized in 3D from any viewpoint. Users can thus make their own experiments about brush clearing and acquire a better understanding of its impact especially in the interface between forest and dwelling. The interactive 3D visualization permits a good understanding of the process and reinforce the desired pedagogical impact by its realism.

\section{Forest clearing in environmental management}

The French law sets owners to clear the undergrowth on all terrains in urban areas or plots, built or not. Each land owner must clear the undergrowth in a radius of 50 meters around a building (but this can be increased by the local council) and up to 10 meters on each side of private access to the site, even on neighbouring properties if necessary. The law defines undergrowth clearance as the whole set of operations "whose objective is to decrease the intensity and to limit the propagation of fires by the reduction of plant fuels, by guaranteeing a rupture of the continuity of vegetable cover and by carrying out the pruning of the maintained subjects and the elimination of remnants of cuts". The Prefect in each department adopts the procedures of application of this article by taking account of the characteristics of each massif. Practically, it implies to cut down to the ground herbaceous plants, shrubs and some trees. The large remaining plants must be distributed so that the propagation of a fire cannot be done from one to the other or from a tree to the dwelling. Some districts have a Plan of Prevention of the Risks (PPR), in which undergrowth clearance can be treated with particular measures. Unfortunately, a study of the Ministry for the Town and Country Planning and Environment showed that this obligation to clear undergrowth is poorly respected by the owners who are subjected there, this low rate of application being partly ascribable to a lack of information (Agency MTDA, 2001).

\section{Our solution}

Consequently, there is a need of means of information to demonstrate the importance and efficiency of brush-clearing towards decision makers, elected representatives or private landowners. This is why we have developed a pedagogical tool designed for this kind of people in collaboration with the French firemen of the Service Départemental d'Incendie et de Secours du Département des Bouches du Rhône (SDIS 13). This tool allows to realistically depict in 3D the devastating effects of forest fire under different conditions of brush clearing, based on fire simulation and data extracted from a GIS. A strong psychological impact can be achieved because we can show to people how brush clearing is important by taking as an example their own district or even their own house. Our application is composed of four main parts. First, an embedded Geographic Information System to store various geographic data like terrain or 
buildings, second, a forest fire spread simulation, third, a realistic real-time 3D visualization, and finally an intuitive human-machine interface that allows to simulate brush-clearing very easily.

\section{Geographic Information system}

In order to permit the 3D visualization of real terrain data, we have embedded in our application a simplified GIS that allows the use of various databases from the French Institut Géographique National (IGN):

- BD ALTI: this database contains Digital Elevation Models that covers the whole country with a sampling rate of one point every 50 meters;

- BD ORTHO: aerial ortho-rectified photographs covering the whole country with a precision of one pixel for 50 centimeters;

- BD CARTO: vector description of the location of various geographic elements like roads, railways, rivers, power lines, buildings, etc.

\section{Forest fire simulation}

As we intend to simulate the effects of forest fire under different brush clearing conditions, it is necessary to reproduce as close as possible the behaviour of a real fire.

Many forest fire models have already been developed. These models can be classified in two kinds (EufireLab, 2002a). The first kind of model is based on knowledge coming from experimentations (EufireLab, 2002b). The second one makes use of physical laws (mass, energy, moment, etc.) which lead to expensive computations and memory cost.

As we needed in our application a fast-responding simulation with reasonably realistic behaviour, we choose the empirical model BEHAVE (Andrews, 1986) based on Rothermel equations (Rothermel, 1972). These equations are solved over the terrain thanks to a finite differences approach. The terrain is uniformly discretized as a 2D grid which cells contain physical parameters like fuel, terrain slope, etc. Fuels characteristics are extracted from a database from the Inventaire Forestier National (IFN) which describes forested areas of homogeneous species (Figure 1).

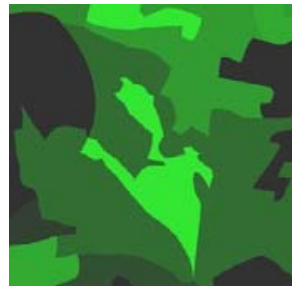

Vector map
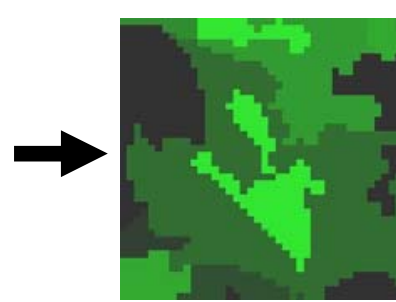

Discrete map 
Figure 1. Repartition of forested areas from the IFN database. The vector regions of this database are discretized on the simulation grid to provide one fuel information for each grid cell.

During simulation, fire propagation from cell to neighbouring cells is computed by Rothermel equations according to the speed and direction of the wind, relief, remaining fuel in the cells and elapsed time since the fire broke out.

Since our application is designed to be a pedagogical tool, we have made the fire simulation control very simple, without requirement of any scientific understanding. Its use is actually intuitive because the user only needs to define wind speed and direction, and to define the points where fire starts. Then the simulation can be started and the computed values are automatically displayed as 3D computer graphics.

\section{Realistic 3D visualization}

We have added in our application a 3D display that enables a realistic visualization of the landscape and forest fire. The display has been optimized to allow real time interaction to the user who can observe the 3D scene from any viewpoint.

\section{D terrain}

The IGN database BD ALTI provides the elevation information of the French territory with a density of one point every 50 meters. We use these data to reconstruct in 3D the terrain surface by joining the elevation points with triangles. In order to improve the realism, we map as textures on this surface the orthophotos from the BD ORTHO database (Figure 2).

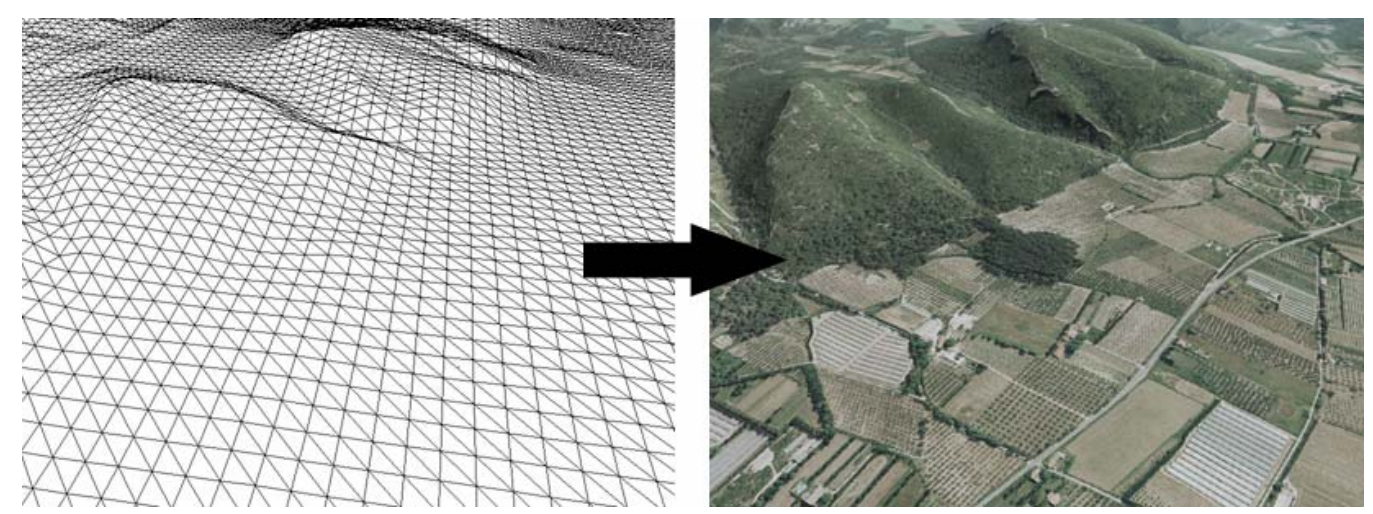

Figure 2. Creation of a 3D terrain from the IGN databases BD ALTI and BD ORTHO.

We also use data from the IGN database BD CARTO to build a much more realistic 3D landscape. We use the location of buildings, stored in this database, to reconstruct these buildings in $3 \mathrm{D}$ by extrusion of their 2D shape.

Moreover, we use geolocalized name information stored in the BD CARTO to facilitate the orientation of the user by displaying legends on various key points of the 3D landscape (official buildings, water tanks, watchtowers, etc.). These legends are hypertext links that can provide more information when selected, like pictures, commentary, etc. 


\section{Flames and smoke}

In order to display a forest fire in computer graphics, we use data computed by the fire spread simulation. The simulation fills the $2 \mathrm{D}$ grid with time evolving information about flame height in the burning areas. We use this grid to display flames and smoke in the corresponding areas. These computer generated graphics are produced in real time thanks to particle systems. This animation technique defined by (Reeves, 1983) uses a collection of particles characterized by attributes such as position, velocity, size or colour. These particles are moved with time according to their attributes. They are displayed as quadrilaterals texture-mapped with videos of real flames and smoke (Figure 3). These textures contain an alpha-channel for transparency effect.
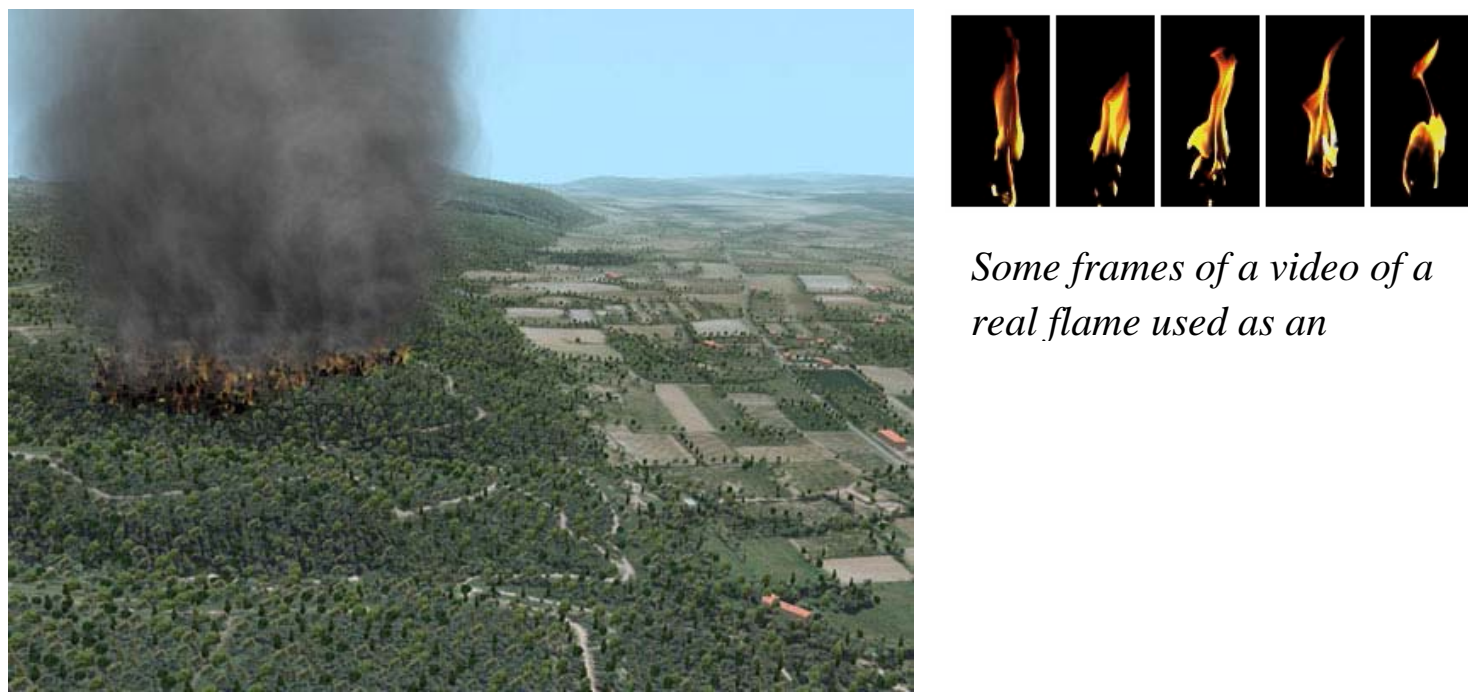

Some frames of a video of a real flame used as an

\section{Figure 3. Computer generated flames and smoke.}

The height of the computer graphics flames is given by the fire simulation. Flames with different heights can be displayed by simply changing their quadrilateral size. The orientation of flames and smoke is computed according to the direction and speed of the wind.

\section{Intuitive Human-Machine Interface}

The user interface of our application is very simple to use, as even a non-specialist must be able to handle it. The user can visualize in 3D the whole French territory and select the area where the forest fire has to be simulated.

Initially, the fuel repartition on the terrain is given by the GIS from the IFN. However, the user can modify the fuel to simulate brush clearing or the planting of new species. This can be done very intuitively by using drawing tools directly on the 3D terrain. A toolbox in the interface is dedicated to these operations. The user can select the new forest specie in a list of this toolbox that also contains the special "no combustible" element. Then, this new fuel can be placed by simply drawing with the mouse on the 3D terrain with an adjustable-size brush. In order to simulate brush-clearing, it only needs to draw in the selected area with the fuel "No combustible" or "Short grass".

Another toolbox allows the user to define the simulation parameters. It is possible to define the points where fire starts by directly clicking on these points with the mouse on the 3D terrain. The simulation can then be run, be evolved by time increments of one minute, ten minutes or one 
hour. It can be stopped or started again. The user can add new fire starting points at any time during the simulation, for example to simulate fire jumps. Wind direction and speed can be modified at any time. However, other weather parameters such as rain are not taken into account.

\section{Results}

The Figure 4 shows an example of virtual brush-clearing. On the left images, we can see the fuel map as edited by the user, using the mouse and giving properties as in a painting program, with the underlying terrain in transparency to guide him. On the right images, we can see the result of a fire taking into account their respective fuel map. In order to test the brush-clearing influence, we have ran two separate fire simulations, first without brush-clearing and second with the clear of undergrowth around buildings. Initial conditions are identical, setting the wind speed to $20 \mathrm{~m} / \mathrm{s}$ and the same starting point of fire (down left on the image). The resulting images are taken after a simulated hour of fire propagation.

On the upper images, the simulation is done in real conditions of location and type for plants. We can see that the built areas are reached by fire. On the lower images, the user modifies the characteristics of the fuels on the ground surface, simulating a brush-clearing in a radius of 50 meters around buildings, thus respecting the French law. In this case, the dwellings are safely preserved and the fire can not continue its walk in the vicinity of buildings because of the lack of fuel, so it is constrained to go round the brush-cleared areas.
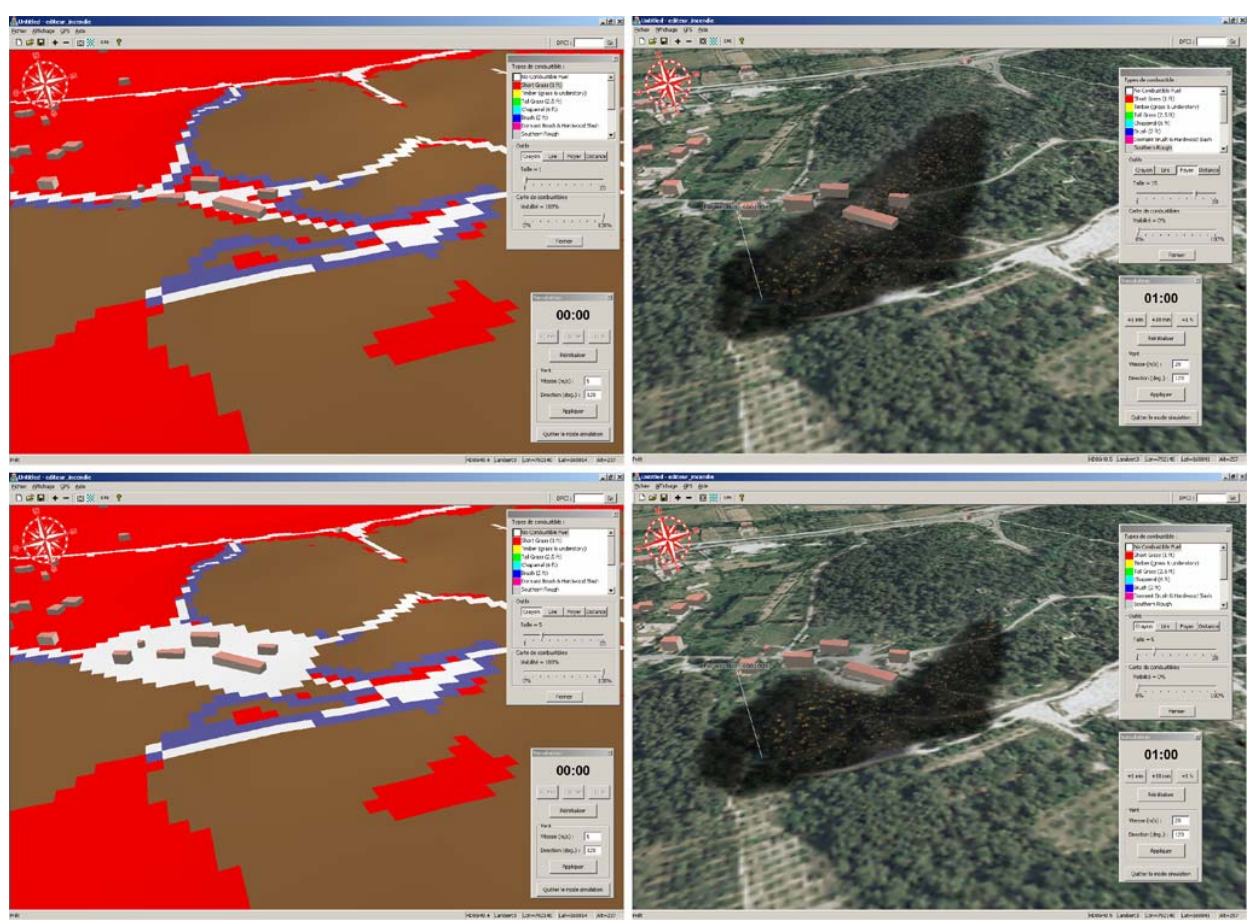

Figure 4. Forest fire consequences on a terrain let rough (up) and brush-cleared (down). 


\section{Conclusion}

In this paper, we have presented a new software to help sensitizing and decision-making about the brush-clearing process necessary to avoid forest fires. It enables to visualize in three dimensions any given area in France and to simulate fires there. Very intuitive tools let the user modify the vegetation on the ground, either by virtually planting new kinds of trees or by cutting existing ones, in order to visualize the impact of such choices on a forest fire.

The 3D in our application is very important. It is first of all an essential element with respect to simulation computations because the propagation of fire depends on the relief of the terrain. Indeed, ascending fires burn as faster as the slope is strong, whereas a fire going down is slowed down. Moreover, the 3D visualization of the landscape from any viewpoint allows a better comprehension of the map. This better perception of the relief allows to better estimate the access difficulty to a zone for a rescue team, which is not always easily possible on a traditional two dimensional map. Finally, the visual realism of the 3D plays a very important part in the psychological impact required by our application which is dedicated to be a teaching aid. In the continuation of our work, we are thinking of using a richer fire propagation model which takes better into account the Mediterranean specific trees with the help of specialized research laboratories like the CEMAGREF in France.

\section{Acknowledgements}

We want to thank the Service Départemental d'Incendie et de Secours of the Département des Bouches du Rhône for their careful attention for this work. We thank the Centre Régional de I'Information Géographique of the region Provence-Alpes-Côte-d'Azur which provided us any data from the IGN which were necessary. 


\section{References}

Agence MTDA (Ministère de l'Aménagement du Territoire et de l'Environnement) (2001) Propositions d'amélioration de la mise en application de la législation sur le débroussaillement en fonction de l'analyse d'expériences en retour - $77 \mathrm{p}$.

Andrews P.L. (1986) - BEHAVE: fire behavior prediction and fuel modeling system - BURN Subsystem, part 1 - General Technical Report INT-194. Ogden, UT: U.S. Department of Agriculture, Forest Service, Intermountain Research Station, $130 \mathrm{p}$.

CartoHub (2006) - www.bitmanagement.de/documents/PM_EMI_E_20050825.pdf

EufireLab (2002a) - Eufirelab : Euro-Mediterranean Widland Fire Fire Laboratory, a "wall-less" Laboratory for Widland Fire Science and Technologies un the Euro-Mediterranean Region; Deliverable D-03-01; www.eufirelab.org

EufireLab (2002b) - Eufirelab : Euro-Mediterranean Widland Fire Fire Laboratory, a "wall-less" Laboratory for Widland Fire Science and Technologies un the Euro-Mediterranean Region; Deliverable D-03-03; www.eufirelab.org

Picard C., Giroud F., Charrel B., Raffalli N. (2004) - La simulation feu de forêts : FIRETACTIC - Centre d'Essais et de Recherche de l'Entente, Entente Interdépartementale, Sécurité Civile, 13120 Gardanne, Actes de la 4ème conférence Environnement et identité en méditerranée.

Prométhée (2003) - banque de donnée des incendies de forêts en région méditerranéenne ; Bilan 2003 - http://www.promethee.com/

Reeves W.T. (1983) "Particle Systems - A Technique for Modeling a Class of Fuzzy Objects", Computer Graphics, vol. 17, no. 3, pp 359-376.

Rothermel R.C. (1972) - A mathematical model for predicting fire spread in wildland fuels Research Paper INT-115. Ogden,UT: U.S. Department of Agriculture, Forest Service, Intermountain Forest and Range Experiment Station; 40 p. 